\title{
Gender issues on change agenda - Practising intersectionality in action research
}

\section{Tuula Heiskanen, Katri Otonkorpi-Lehtoranta, Minna Leinonen and Hanna Ylöstalo}

Changing gendered conditions in organizations is a challenge. Previous intervention processes have shown that it is difficult to raise gender inequality issues in organizations, and even more difficult to keep them on the agenda. According to the World Economic Forum's Global Gender Gap Report 2013, ${ }^{1}$ the Nordic countries were ranked the most gender-equal region in the world in 2012. Despite the fact that the national policies on gender equality vary in the different Nordic countries, they also have many characteristics in common (see e.g. Julkunen 2010; Kautto 2001; Sigurðardóttir 2010). Although the Nordic countries have consistently been ranked the highest in the world regarding gender equality, they still face various persistent problems (Rantalaiho \& Heiskanen 1997). Paradoxically, the relatively good state of affairs may be a hindrance to improving conditions. In Finland, the site of this study, for example, there is a strong belief that gender equality has already been achieved, and it can therefore be difficult to motivate people to promote it further. Gender equality might also be counter to the interests of some; for others, it may just seem irrelevant or unimportant. All these issues produce challenges to promoting gender equality in organizations.

In this article, we will focus on the challenges, choices and dilemmas that we as researchers working in the gender equality development field have faced in organizations. The incentives for our work come from two sources: from the tradition of action research and from the inheritance of feminist methodology. Both traditions have some converging aims, but exploring these aims as mutually enriching has remained underutilized. According to our observations, the recent trends in the intersectionality debate seem to raise challenges to practical equality development work which have not been dealt with in the literature thus far. Using the Finnish Defence Forces (FDF) as an empirical example, we will investigate how to handle intersectionalities in the orientations and positioning of the organization's members when doing feminist action research in workplaces.

\footnotetext{
${ }^{1}$ http://www3.weforum.org/docs/WEF_GenderGap_Report_2013.pdf.
} 
The article proceeds by presenting some views of the equality conditions in the FDF, which are based on the survey data. An extract from the data introduces various equality perspectives in the organization under scrutiny. Diverging equality perspectives continue to be addressed in the following sections, which use extant literature to search for tools for supporting equality work in different contexts. The focus of these sections lies in action research and discussions on intersectionality. We ask how feminist action research as a practically driven research strategy could benefit from theorizations of intersectionality in developing equality in organizations.

Finally, we present an empirical case in which the organization's equality development work is supported by action research methodology. The specific aim of the equality development work was to prepare a written equality plan which will require the workplace to introduce actions and measures in order to advance equality and also to follow and report on the progress and update the plan. This is also what happened in practice. Starting from this pilot project with a couple of the organization's units in 2007, nowadays the General Headquarters of the FDF ensures that each unit makes its own equality plan. The discussion draws attention to how action research and specifically the work conference method can facilitate organizational change. The overall aim of the article is to contribute to the discussion on how the intersectionality lens can inform organizational change via action research and what kinds of problems practising intersectionality in action research encounters.

\section{Diverging perceptions of gender equality in the workplace}

We present a case study from the FDF as an example of how the issues of gender equality and intersectionalities are encountered inside an organization. Over the past six years, we have been doing research and development work related to gender issues, work and family, and leadership in the FDF organization. All projects have been driven by the action research and/or gender and equality point of view. In the context of the FDF, gender, occupational status, age, years of service and military rank are interrelated in a complex way and this complexity is deeply rooted and maintained on the one hand in the formal structures of the organization, division of labour and work obligations, and on the other hand in the everyday work practices, processes and actions. The FDF is a very homogenous organization in terms of race and ethnicity. ${ }^{2}$ The emphasis of this article is on the complexity of gender, age,

\footnotetext{
${ }^{2}$ The racial and ethnic diversity of the workforce will, however, be increasingly an issue in the FDF. In 2005 a project called "Advancing Diversity in The Finnish Defence Forces" was launched. The proportion of immigrants will rise among employees and conscripts in the future.
} 
occupational status and the division of civilian and military employees. According to earlier findings, these categories are crucial elements in creating and maintaining inequalities in military organizations (Leinonen et al. 2008; Tallberg 2009; Persson 2011).

In order to give some empirical illustrations of practising intersectionality in action research, we used two different datasets. One dataset (see later in the article) is based on the researchers' field notes and the participants' outputs from the work conference arranged in the FDF in 2008 (Leinonen et al. 2008). The other dataset consists of the survey data on well-being and gender equality at work (Leinonen et al. 2012). The data was collected by distributing questionnaires to the whole salaried personnel in the FDF in 2011. The response rate was $54 \%$. $^{3}$ In addition to structured questions, the survey included one open question - on how to develop equality or what kind of feedback one would like to give - to which there were 1,233 answers. ${ }^{4}$ For the aims of this article, we utilized the findings of the survey concerning perceptions of gender equality and its open answers on perception of equality and prevailing inequalities. The analysis of open answers attests that different positions in hierarchy, civil/military tasks and gender and age groups perceive the concept of gender equality differently. Our conclusion of this is that the views of gender equality are based on different ideas of equality that may contradict each other, in which case defining gender equality is also a question of power, and in the end, whose definition wins.

If we consider the overall view on gender equality in the organization, we notice that the vast majority of the personnel were pleased with the level of gender equality in their workplace. However, evaluations of gender equality are quite different when the gender of the respondents is taken into account: nearly half of the women do not consider the gender equality situation a success, whereas only one man in ten is similarly critical. On their answers to the open question, male officers and other military men in particular thought that gender equality can be considered and should be examined in the organization only as equality among one occupational group:

"Implementing equality would require more information for employees. Now gender equality is entangled with job descriptions of different tasks. Different occupational groups have got different tasks

\footnotetext{
${ }^{3}$ The data clearly represents the proportions of occupational and gender groups.

${ }^{4}$ The data was then given different codes according to the content of the answers. The codes utilized in this article include all the open answers that concern perceptions of equality between occupational groups and genders (225 answers all together). Each code was split into smaller groups by gender, age, civil/military division and hierarchical position in the process of analysis to find differences between staff members.
} 
and education standards (equivalent to nurses and doctors, for example). At the same time people make labour market policy to drive their own viewpoints. " (A male senior officer)

The quotation above shows that the structure of the organization and centrality of officers in it were taken for granted. Also, perceiving equality as an identical qualification for both genders was most common among male soldiers. It was seen that women especially should not benefit from having different physical qualities because of a range of different standards set for the genders. In this case, gender was seen as an issue that should be totally invisible in the organization:

"Equality means that you don't think anything related to the gender of the employees in the army. Military rank or education is the only thing that counts, the rest of the features are always personal characteristics." (A male younger officer)

Further, we see a great variation in the degree of criticism when we look at women in civilian and military positions; overall, civilian women are much more critical towards the state of gender equality than women in officer or other military positions. Of civilian women, experts and office workers are the most critical groups. As the quotation below shows, gender and occupational status are closely interrelated in the experiences of inequality:

"A female civilian worker does not get equal treatment compared to officers or even to male civilian workers in any sector. For example, the tasks of a female civilian are classified under office tasks with a lower salary, although in the case of officers and male civilians the same tasks are classified under expert tasks with a higher salary. This happens even if the educational level/the requirement of work experience and the tasks are on the same level or the same between female and male civilians and officers. " (A female civilian worker)

Due to the education system and career planning of soldiers and officers, in particular, hierarchy and age are interwoven. Officers start Military Academy and work after that on average at the same age. They also go through the same educational system and participate in the same courses at certain stages of their career, which gives them the opportunity to apply and be chosen for particular military tasks with a specified military rank required. Ultimately, a promotion in military ranking requires a certain amount of years of service in given military tasks. This means that aging, higher education, higher military rank and career promotion in terms of completing more demanding tasks and climbing up the organizational hierarchy go hand in hand. For other soldiers and especially for civilian workers the situation is different. As the quotations below show, aging and the resulting extensive work experience is not rewarded in the 
same way for all. Age seems to create divisions not only between women and men, but also among women:

"My opinion is that this age equality falls on women more than on men. A woman becomes a bad employee when she gets old and sick." (A female civilian expert worker)

"I would like to draw attention to the inequality between women (appearance and age discrimination)!" (A female civilian office worker)

"My gender and age have been a distinct advantage in my work, but I have noticed that in obtaining a permanent job being a woman and young is a problem." (A female special officer)

Among men in civilian and military positions, the variation in the degree of criticism towards the state of gender equality is much weaker: only civilian men in office work differ strongly from the male average. Figure 1 highlights and resets the question posed by Yuval-Davis (2006) on how a specific dimension of inequality - such as gender in this example - is distributed and relates to different dimensions of power and exclusion (cf. Choo \& Ferree 2010, 135).

Civilian employees (especially women), instead, emphasized gender equality as having two dimensions in which both gender and occupational groups as intersecting categories are important. Therefore, according to this understanding of equality, one cannot close one's eyes from these simultaneously influencing inequalities; it is instead necessary to challenge the prevailing structure and organizational practices across the horizontal and vertical hierarchies and structures of the organization. 


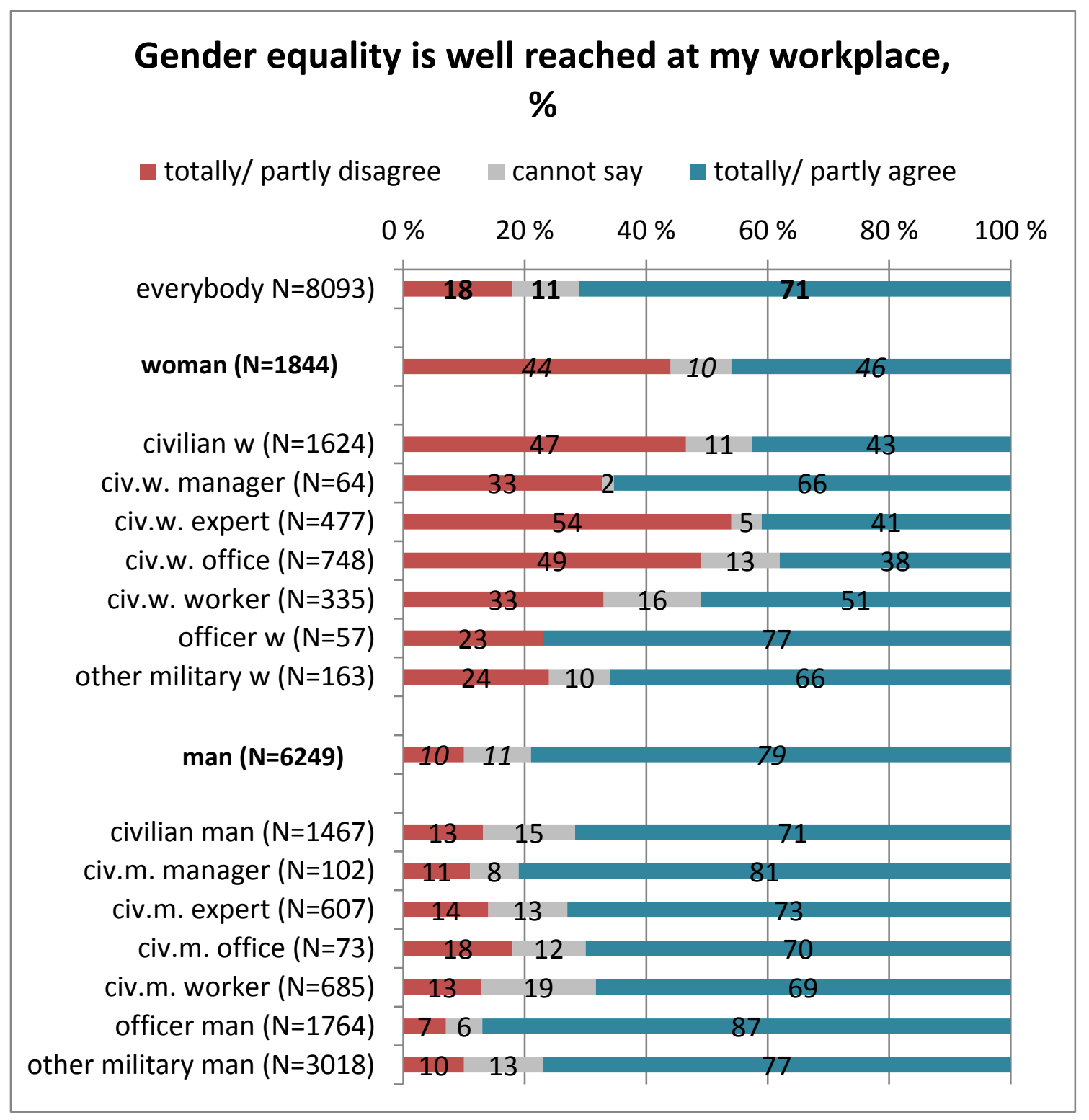

Figure 1. Perceptions of the level of gender equality according to the categories of gender, the civilian/military personnel division and hierarchical position.

This illustration of the varying views on the status quo of gender equality in the FDF organization leads us to further ask how (and why) these perspectives are so different and how they could be dealt with in action research. The varying views give us the indication that the social positions behind these categories also differ from each other. Social positions, in turn, are produced and maintained in everyday practices, processes, actions and meanings that cannot be revealed and changed by survey data alone. 
Our research is rooted in both action research and feminist studies. The action research tradition that the research group leans on is based on the idea that individuals have diverging perspectives on affairs and that these diverging perspectives should be heard and shared in order to carry out an organizational development process successfully. Therefore, dialogical methods and learning from others constitute the core element of the process (Gustavsen 1992). Action research is a participatory and democratic process concerned with developing practical knowledge in the pursuit of worthwhile human purposes, grounded in a participatory worldview, as Peter Reason and Hilary Bradbury (2001, 1-2) define its general aim. According to the definition, action research seeks to bring together action and reflection and theory and practice in participation with others and in the pursuit of practical solutions to issues of pressing concern to people. Action research aims to work towards practical outcomes and create new forms of understandings (ibid.).

Action research aims to empower people, give them a voice and platform for participation and seeks to hear and make use of their experiences to generate change. Inspired by the linguistic turn in social sciences, a number of researchers have started to apply dialogical methods in their action research undertakings. The methods as such are based on different theoretical backgrounds concerning both dialogues and organizational change (Aagaard Nielsen \& Nielsen 2006; Kuusela 2008; Lehtonen \& Kalliola 2008). Action research also focuses on problematizing power relations not only between people participating in the research, but also in the research process itself. Feminist studies share many of these ideals (Gatenby \& Humphries 2000, 90; Maguire 2001, 64-65). Making power relations visible in the research process requires the researchers to have the capacity to reflect on how to carry out the research so that the researchers' choices support the objective of promoting social justice (Madriz 2000, 836842).

Even though feminist action research is quite rare, some research processes have been conducted using this approach. Feminist researchers have developed action research methods towards gender sensitivity (e.g. Coleman \& Rippin 2000; Ely \& Meyerson 2000; Maguire 2001; Meriläinen 2001; Meyerson \& Kolb 2000; Reid 2004). This has been carried out, for example, by taking into account the relationship between gender, organizational structures and communication processes in the theoretical and practical implementation of the research (Drejhammar 2001; Heiskanen 2006); by supporting gender awareness in the context of the discussion about employer brand (Lundkvist \& Westberg 2012); or by integrating gender perspectives into regional innovation systems with the aim of developing gender-aware 
organizations (Andersson \& Amundsdotter 2012). Feminist theories can help unmask taken-for-granted social practices that reinforce hierarchies and exclusion while revealing new social change strategies that can directly contribute to the transformative aims of action research (Frisby et al. 2009, 25).

In organization studies, conventional research approaches in treating organizational members as objects of research run the risk of replicating the inequalities of the workplace through a researcher-researched hierarchy and therefore unintentionally minimize the change-inducing possibilities of the research. Action research, in contrast, involves developing action strategies aimed at generating organizational change through the process of research intervention (Coleman \& Rippin 2000, 573-574; Svensson \& Aagaard Nielsen 2006).

Some feminist action researchers have adopted a "dual agenda for change". By addressing issues of gender equality in organizations, the dual agenda suggests that organizations can develop strategies that lead to more diverse and integrative workplaces, which in turn will lead to an improved capacity to meet instrumental business goals (Rapoport et al 2002, 20-22). However, this involves a risk that the business piece of this approach has greater legitimacy than the gender piece, and gender might be dropped out of the picture (Coleman \& Rippin 2000, 574, 577). Therefore, researchers have to be very cautious about how they represent their goals. Firstly, access to the organization may depend on how the objectives are framed (Lundkvist \& Westberg 2012). Secondly, due to ambiguity in goals, researchers might end up perpetuating, rather than combating, inequalities in the workplace (see also Lorbiecki \& Jack 2000).

As Gill Coleman and Ann Rippin (2000, 584) have noted, it is difficult to work on gender issues inside organizations in order to change the entrenched systems of power and engage people in addressing an aspect of organizational life that is pervasive. It is also challenging because change is uncomfortable and threatening for many, or at least for those in privileged positions. In the process of change, the gender concept gets lost very easily because people prefer not to talk about it or keep the discussion at the policy or society level (ibid).

The relationship between theory and practice has been close in feminist research, as well as in action research. When practising feminist action research, the researcher has to be attentive to, firstly, how to produce knowledge that men and women can use to improve their work environments themselves; secondly, how to use participatory and empowering methods of gaining knowledge; and thirdly, how to develop a critical perspective on dominant practices and circumstances and to search for a change to prevailing inequalities. In this article, we seek to shed light on what kinds of dilemmas the interventions 
and processes of this kind encounter in the field where the researcher faces all the diverse, ambiguous and often competing interests and perspectives of the subjects concerned.

\section{Intersectionality on the change agenda}

In contrast to a survey or interview-based research, in an action research setting and from the fieldwork point of view, it is not possible at the analytical level to exclude some factors or elements and focus only on some variables, for example, on how gender and age are connected with inequality experiences. In fieldwork, researchers confront the intersubjective nature of social life as such. For ethnographers, depending on their research aims and framework, it might be legitimate to stand aside and be as inconspicuous as possible, whereas this is not the case for action researchers seeking change. By confronting all the various expectations of the people concerned, action researchers are forced to react and to respond. An action research process can be seen as a dialogical process structured by both the researcher and the researched. Therefore, power relations are not stable but under construction all the time throughout the process.

In the context of advancing gender equality in a workplace, researchers have to deal with different interests and definitions of equality. Gender equality development work, as well as feminist gender equality research, has different perspectives on gender and equality. Gender equality development work is shaped by the meanings given to "gender" and "equality": different perspectives of gender equality have different goals, as well as different strategies to promote gender equality. Equality can be interpreted, for example, as women's and men's equal opportunities, which are based on their sameness as human beings. Women and men can also be regarded as different but equal or equality can be seen from several perspectives, such as gender, age, ethnicity and sexuality. Each of these interpretations has different purposes and different outcomes in gender equality development work. Depending on the understanding of equality, equality work can focus on, for example, positive action, such as gender quotas, or preventing discrimination, or both (Ylöstalo 2012).

Therefore, by taking into account different aspects and conceptualizations of equality in an intervention process, it is possible to make visible the complexity of the organizational life and the underlying assumptions and power relations behind practices. In recent years, the complexities of gender issues in organizations have often been treated within the framework of intersectionality. The concept of intersectionality has been presented as "a tool to analyze, how sociocultural hierarchies and power differentials, which produce in/exclusion around discursively and institutionally constructed 
sociocultural categories such as gender, ethnicity, race, class, sexuality, age/generation, nationality etc interact" (Lykke 2005, 8). These discussions have been concerned with what social categories should be included in scientific examinations, on the one hand, and in the law and regulations, on the other hand (Yuval-Davis 2006, 201-203), whether a coherent framework to approach the intersectionality issues can be found (Acker 2006a), what benefits the broadening of the equality concept might bring with it and what the risks are if, in the spirit of intersectionality, a notion of multiple discrimination is adopted as a guiding principle without specific attention to gender (Thorvaldsdottir 2007; Verloo 2006).

Joan Acker (2006a, b) has tried to overcome the somewhat scattered discussion around the relevant and less relevant social categories by introducing her concept of inequality regimes. Her criticism towards the intersectionally informed inequality analyses is that they have focused on one or another social category rather than attempted to study inequalities as complex, mutually reinforcing and contradicting processes $(2006 \mathrm{a}, 442)$. Her main focus is on organizations, which is interesting from the point of view of this article. She defines inequality regimes as "loosely interrelated practices, processes, actions, and meanings that result in and maintain class, gender, and racial inequalities within particular organizations" (ibid., 443). Based on her analysis, her guide to studies is to pay attention to what ways gender, race and class inequalities are simultaneously created in the fundamental construction of the working day and of work obligations. For the purposes of our study, this advice is worthwhile because in action research we have to get close to the daily practices of the organization.

Making intersectionality into more than a buzzword (Davis 2008) requires further theoretical, methodological and empirical work. Leslie McCall (2005) was among the first scholars to introduce intersectionality as a series of methodological approaches to expand readers' understanding of how to study intersectionality and to show its potential capacity in research on the multiple, intersecting and complex social relations. McCall $(2005,1772)$ considers the complexity that "arises when the subject of analysis expands to include multiple dimensions of social life and categories of analysis". This notion of the complexity of the relationships among the multiple dimensions of social relations, and the need for multiple approaches as a consequence of it, is at the core of McCall's article. As such, her article inspires us to ask how this complexity applies to action research and development work.

The concept of intersectionality addresses a central feminist concern about capturing multiple positionalities. It has also opened up possibilities for gender-sensitive action research projects in which men or sexual and/or gender minorities can also be the subject in focus (Frisby et al. 2009, 18-19). In action research, people work together from very different social positions. Action researchers can derive 
from the concept of intersectionality a guide to take the complex relations between these social positions and categories behind them as a starting point while striving for change. Our preliminary understanding is that in the FDF organization, there are practices, processes and rules that result in divisions according to gender, occupational status, civilian/military divide and age. It is an empirical question in what ways these are related to each other to form, what Acker calls, inequality regimes.

\section{Intersectionality in the work conference method}

Work conference is an action research intervention method for workplace or inter-workplace development that aims to find solutions for pre-selected (practical) problems or issues. It is based on democratic discussion and therefore is a participatory method to develop workplace practices. For us, the most familiar formulation of democratic dialogue is the one developed by Bjørn Gustavsen (1992, 2001). Gustavsen has conceived the rules of democratic dialogue that emphasize two-way communication, all concerned (by the issue under discussion) with the right to participate, work experience as a basis for the right to participate and to be heard and the same status of all participants in the dialogue arenas. According to Gustavsen, dialogue should always continuously generate decisions that provide guidelines for joint action. The work conference method aims to provide a chance to the different occupational/functional groups of the organization to speak openly and discuss from their own point of view the issues at hand, and in this way cut across prevailing/dominant hierarchic boundaries (Lehtonen 2004). These hierarchic boundaries at a workplace can also follow - and often do so - social categories, such as gender, race and class. The practical organizing of a work conference seeks to support this boundary crossing.

A work conference is typically made up of the interplay between workshops and plenaries. In the workshops, small groups of people discuss the main theme of the work conference. Every workshop is followed by a plenary where all the small groups present their summaries of the discussions. The first workshop is for creating a vision of the future. In the context of equality, this means a vision of a workplace in which all members of the work community are equal and no discrimination exists. People in the small groups are asked to envisage their ideal and equal workplace. The group chooses both a secretary and a chair, and the latter also introduces the main ideas of the group's discussions in the plenary. This first workshop is organized in homogenous groups, that is, participants are divided into groups by work position, gender or some other aspect that is seen as an important category according to the objective of each work conference. The aim of working in small groups with a certain composition is to assure a safe and open atmosphere for the participants to discuss freely their experiences and 
thoughts and thus empower certain groups. In the first plenary, the ideas of all groups become visible for all the participants.

The second workshop is for discussing the obstacles to improving conditions and achieving the vision. Participants from different work positions, organizational hierarchical levels, organizational functions and gender, to name a few, are brought together to share their experiences with others whose backgrounds differ from their own and to discuss the challenges in the way of the ideal workplace envisaged earlier.

The third workshop is for finding means to overcome the obstacles brought up earlier. The group is often organized in the same way as the first workshop. Now the emphasis is on practical and concrete actions. Discussions in small groups and plenaries will give the participants ideas for producing a shared view for advancing development work and for drawing up a concrete action plan for the participating organization. At the end of the work conference, participants should have a mutual understanding and idea of how the development work is to be continued.

The work conference method is an action research intervention that uses social categories as sources of diverging experiences and perspectives. As such it allows intersectional usage. Our application represents one possible way to use the method intersectionally. In our case, a survey and interviews in the defined units of the FDF preceded the action research stage and gave guidelines for the focus of the action research. As a very hierarchic and extremely gendered organization, the army gives us an excellent example to highlight the intersectionality of the work conference method and to consider what benefits can be achieved by working in the interplay between small groups and plenaries.

\section{The FDF: The empirical case}

The FDF is a strongly male-dominated organization that divides its personnel into civilian and military personnel groups; women are mainly represented in the civilian groups. The organization is going through structural changes, and there has been a decline in the number of civilian jobs. At the end of 2012, the FDF employed 14,046 people: 8,673 were soldiers (officers, officer specialists, warrant officers, non-commissioned, contractual military personnel) and 5,373 were civilians. Additionally, a maximum of 1,000 people at a time serve in crisis management operations. The Finnish labour market is very highly gender segregated, and this also applies to the FDF. Out of the whole salaried personnel, the proportion of women was $19.6 \%$. Women mostly work in civilian positions in the support sector 
(especially in office work, financial administration and catering services). The proportion of women among soldiers was less than $4 \%$ (mostly non-commissioned), whereas about half of the civilians (45.5 $\%$ ) were women (The FDF, Annual Report 2012).

The work conference to be described here was organized in a unit of the FDF as part of an action research project that focused on gender equality (Leinonen et al. 2008). It aimed at finding development objects together with the personnel and creating the basis for equality planning. ${ }^{5}$ The permission to conduct the research was granted by the Defence Command Finland. At the workplace level, the contact person gave the researchers a list of persons who had voluntarily signed up for the work conference. This enabled researchers to make groups in advance in order to meet the aims of the work conference and the criteria of the method. There were 20 participants altogether. Participants were women and men, both soldiers and civilian workers. All the female participants were civilians with the exception of one soldier. Men were mostly soldiers, but there were also a few civilians. Participants were divided into different types of groups. In the three consecutive work conference group sessions, there were five groups at every stage. At the first stage, the groups were organized according to gender. There were two women's groups, of which the first one included three civilians and one soldier and the second one included only civilians. The other three groups were made up of men. There were two soldier groups and one group with a majority of civilian employees and one soldier. In the later stages, the groups were mixed so that they included women and men from different positions. The fact that there were fewer female participants sometimes created a situation in which there was only one woman in some groups.

In the following section we illustrate some of the discussions in the different sessions in order to show the role of the social categories and compositions of the groups to highlight the dynamics and substance of the discussions and the potential of the method to challenge prevailing organizational practices.

\section{First workshop: Creating a vision for a good and gender-equal workplace}

The general theme of the discussion at the first stage of the work conference was to create a vision for a good and gender-equal workplace. ${ }^{6}$ To illustrate this, we present here the contents of discussions and style of working in two groups. In the group of three soldiers, ${ }^{7}$ the topic was whether there could be a

\footnotetext{
${ }^{5}$ According to the law, the obligation to draw up a gender equality plan applies to all Finnish workplaces with at least 30 employees.

${ }^{6}$ The task was exactly worded as follows: "Task 1 . You come to work on a beautiful spring morning in 2015. Equality has been achieved in your workplace. What has happened?"

${ }^{7}$ The group was supposed to have five participants, but two people did not attend the work conference.
} 
place for equality in a military organization in which decision-making through negotiation is not inherent to the organization. They also contemplated whether equality should be about individuals or about the organization; in other words, whether equality should be seen from the individual's or the organization's point of view. Thirdly, the group concentrated on career issues with a strong emphasis on the primary position of officer training compared to others. In the group, the chief of staff and a commander of a battalion talked the most, while the third member of the group was quieter. The division of labour followed the organizational hierarchy in the group. The commander of the battalion appointed his superior, the chief of staff, as the chair, and the third soldier was chosen as the secretary. The chief and the commander presented clear viewpoints and the third quieter soldier did not express a dissenting voice. Interestingly, the vision written down and presented in the first plenary did not fully reflect the group's discussions in the workshop, but was more motivated by fulfilling the given task. This can be seen as an expression of military culture, which is strongly oriented towards fulfilling given orders and tasks. This interpretation was also confirmed by our observations from other groups of soldiers.

In the women's group with three civilians and one officer, the focus was strongly on civilians' and officers' different opportunities for self-development at work as well as career progression. The civilians emphasized the difference of the position of civilians compared to the experiences of the officer. The oldest civilian worker took the role of the chair and expert in the group, which conformed with her experience and education. The officer, instead, took the role of the introducer of the group's discussion and conclusions. This follows the general division of labour between civilian workers and officers in the FDF, according to which civilian expertise is acknowledged but, in formal contexts, the soldier supervisor of the civilian expert acts as the introducer. The officer thought that women and men were equal in terms of salary and career promotion (in her own case as well), whereas the civilian workers did not think this was the case. However, the discussion was supportive, and the participants aimed at mutual understanding about the issues under discussion. The women's group wrote down and presented in the plenary that in their vision of an equal workplace there is a possibility for career development for civilian workers and expertise of civilian workers is recognized and utilized in the organization.

To sum up the results from the first round of discussions, it seems that issues like maturity and position in the military hierarchy affected the division of roles and the domination of the conversational space. However, as indicated by the women's group, it was possible to cross the civil-soldier divide by sharing experiences and locating inequalities that were attached to both gender and position. Also, in the men's group in which there were both civilian and military participants, participants were able to discuss across the divide aided by some common ground in their work experiences. However, the discussion did not dwell much on gender equality but rather on other concerns. This was partly due to working in all-male 
or male-dominated work stations and tasks. In another women's group, there were only civilian employees. The discussion seemed open and everybody participated, although some hierarchy could be detected in the division of group roles: the one thought to be the highest in the organizational hierarchy was chosen to chair the session. However, a reason for the selection was not made explicit. Those groups that had female participants and civilian experiences were more likely than others to produce discussions attached to gender and improving gender equality. Male groups and soldiers raised concerns about how well the concept of equality fitted the military organization and about the possibility of favouritism towards women (in the military system).

\section{Second workshop: Obstacles standing in the way of reaching the vision}

The topic of the second session was to discuss matters that hindered or promoted gender equality. ${ }^{8}$ Different sub-themes were allocated to participants to ensure that issues raised in the unit's gender equality survey would be handled. These themes included well-being, equal division of work tasks, pay, and work and family. One of the challenges of comparing these groups is taking into account their different themes: depending on the range of experiences, some issues, such as pay, invite opinions more than others. Therefore, it is also challenging to evaluate participation: for example, in a group discussing career issues, civilian women were somewhat left on the sidelines of the discussion. We wonder whether their contribution to the discussion remained limited because they were lower in the hierarchy or because they did not have good opportunities to build a career in the military. The issue here is whether the structure of the organization is taken for granted or as something that can be changed. Still, the second group session also offered its participants from different hierarchical levels a possibility to understand each other's work conditions by providing a chance to find out how others saw some specific matters under discussion.

The notes of the groups from the second workshops show that gender had disappeared as an explicit issue in the group discussions when women were in the minority. The issues brought into the plenary discussion were predominantly gender-neutral. However, gender was implicitly present in the notes and the plenary discussion, since they included a lot of talking about the division of civilian and military personnel.

Third workshop: Means of overcoming obstacles and a plan for action

\footnotetext{
${ }^{8}$ The task was exactly worded as follows: "Task 2 . Discuss in your group the factors that prevent a good and equal workplace from materializing? What factors in your workplace support the realization of a good and equal workplace?"
} 
The groups were given the task of creating at least two concrete development suggestions to be included in the gender equality plan. ${ }^{9}$ Mixed groups were formed. The group members had difficulties making suggestions because they thought that change would be hard to achieve. For example, in one group, the discussion revolved around the strong feeling that the pay system (based on performance evaluations) was unfair, but no ideas were presented about what could be done about it - except for getting the old system back. Another reason for difficulties was the belief that sufficient guidelines had already been created by the organization. For example, a senior officer in a group was reluctant to create support for reconciling work and family life because he felt the organization functioned well enough in this respect and that this was a question of individual responsibility rather than the employer's responsibility. His group was an illustrative example of an unchallenged privilege: all the participants were male officers who in one way or another defended the system. The viewpoints presented in the group were in line with the answers from the senior officers in the survey and its open question. The senior officers argued strongly for the status quo and their concept of equality was limited to the individuals at the same organizational level and tasks (equality as equals).

As a counterpoint, another group with both female civilians and male officers - one of them was the head of the personnel department - was able to find examples of opening career paths for civilians and suggested that these possibilities should be developed further. It can thus be said that the participant status, work experience and orientation towards development had an effect on the group work results. This group was an illustrative example of positive effects of boundary crossing, which produced and led to clear change efforts.

\section{Discussion and conclusions}

This article has dealt with a case study employing the action research method in the FDF. The work conference method was presented as one possible solution for handling intersectionalities in development work in organizations, especially in relation to equality work. Attention was paid to its special characteristic in creating communication channels across the customary and identifiable boundaries in organizational life.

At the moment, the theorizing of intersectionality lacks praxis, whereas action research lacks intersectionality. From our perspective, it is important to think these ideas through practices that can help development work. It is vital to understand how unequal practices are targeted and to set a starting point for development work. In the muddle of the aspirations of different personnel groups in the FDF,

\footnotetext{
${ }^{9}$ The task was exactly worded as follows: "Task 3. Concrete proposals for development: Discuss in your group at least two specific development proposals for your workplace equality plan.”
} 
we were faced with the organizational cultures and practices that were not always acceptable even to the majority groups. The respondents' underlying assumptions concerning gender and organizational beliefs seemed to affect their answers strongly.

One of the dilemmas the researcher faces in the research and development process is how to make choices that are both attentive to the feminist emancipatory efforts to support social justice and the action research aim to include everybody in the development work and let their experiences and views be heard. In our data, this challenge was highlighted by the FDF personnel's very different views on gender equality and by how the needs to improve career structures and practices stem from different kinds of understandings of what the problem is. Our data illustrates that gender, age, civil/military divide and hierarchical positions intersect in producing inequality effects. Therefore, in targeting development aims, the researcher needs to be aware of the relationship between all these categories.

The intersectionality perspective provides a view on configurations between different social categories. Those configurations can be traced statistically, as Leslie McCall (2005) does, or through concrete actions and practices, as Joan Acker (2006a) suggests. In action research, the focus is on the daily activities of the organization and the aim is a change in some specified condition (Reason \& Bradbury 2001; Svensson \& Aagaard Nielsen 2006). When the objective is development of equality conditions, the research process should be able to bring to the fore the status quo of equality, problems included in it and factors that can either support or prevent improvement in the problem areas.

The action research process is better rooted if the researchers have an understanding of what kinds of processes have led to the prevailing equality conditions, how persistent they seem to be and what kind of mental preparedness for change the organization has. We consider that the idea of inequality regimes suggested by Acker provides a fruitful theoretical tool to grasp the mechanisms and dynamics behind the inequalities. Additionally, we also think that there is a need for concrete methodological tools to trace the configurations behind the inequality regimes.

Our own experiences speak for multi-methods approaches. We think that both statistical analysis, as suggested by McCall, and examination of concrete practices, as suggested by Acker, may have a justified place in the action research process. Preliminary understanding of the context and the prevailing conditions can be achieved by different kinds of data and linked with the work conference method in order to make changes in them. In our case, both a survey and interviews gave guidelines for the focus of the action research stage. 
We started this article by presenting excerpts from a survey conducted in the FDF. All in all, our way of doing action research has been to gain some preliminary ideas of the organization and of the specified conditions before starting the more action-oriented stages of the action research process. Conducting surveys is a useful method for these purposes. Intersectional analysis of the survey data may provide a first approximation of the inequality regimes. Against that approximation it is easier to put into context the events, episodes and information that come up in the action-oriented stages. We think that along with the action research process, it is possible to gain a deeper understanding of the inequality regimes than the statistical approach alone can provide. The potential for the deeper understanding comes from the objective of seeking change through action research. Attempts for change may reveal factors and aspects that remain invisible unless explicitly considered. But, as our case study has illustrated, one has to be aware that the action research process itself and its methods determine how much is revealed and how much remains hidden.

The feedback from the participants revealed that the possibility for boundary-crossing discussions was much appreciated. The objective of creating a safe space for discussions was partly achieved, but not fully: some issues that do not normally come up in the public spaces of the FDF could be handled with the support of the method; in contrast, some participants felt difficulties in expressing their opinions when their supervisors were in the same group. With these limitations in mind, our interpretation is that the intersectional application of the work conference method may help to make visible the habits and routines that are taken for granted.

Formal divisions (civilian/military and hierarchies) were one of the bases that differentiate experiences of organizational life. In addition to these, age and gender were influential, not only through simple main effects but also through interaction effects. In the majority of the male soldier's comments and suggestions, gender, at least their own, was almost a non-issue, whereas it played a major role in all of the women's groups. Both male and female genders could be an advantage or disadvantage for occupational perspectives depending on the tasks, even though military tasks as such belong organizationally and culturally to the male domain. Taking gender as a starting point helps make the male norm visible and enables us to see where women's needs and abilities have been left in the shadows of the FDF's organizational life. Concerning age, it played a different role in military and civil tasks. In practice activities that do not follow intrinsically from the military hierarchy are often treated as if they were and reinforce the division between the valued and less valued groups. As one example, this study has shown that in the public space military persons represent the issues even though civilians might have better knowledge. As another example, the discussions revealed that the lack of openness in promotions gives a strong informal power to senior officers and supervisors in controlling career paths. As a third 
example, the discussions showed that career systems are underdeveloped in civilian tasks. Accumulation of the less favourable conditions constitutes the building blocks of what might be called, using Acker's expression, inequality regimes.

Our case study dealt with a situation in which the organization needed an equality plan. The conducted research acted as a pilot study that gave an incentive for creating development structures (e.g. Lehtonen \& Nakari 2008), which support advancing equality in the organization. In addition, sympathetic and committed persons in the organization who were willing to invest their work efforts to equality issues (see also Blaedel 2013) were a necessary resource for the continuation of the development work.

To conclude, in cases of organizational change, privileges and disadvantages of different groups might get blurred and produce alliances and conflicts between people in different positions in development efforts. A more theory-based awareness of positions and their interconnections will serve the development process by keeping power structures visible and by helping to better understand different

forms of resistance. As a result, the action research efforts might also become better anchored in organizational structures and practices.

\section{References}

Aagaard Nielsen, Kurt \& Nielsen, Birger Steen (2006) Methodologies in Action Research. In Aagaard Nielsen Kurt \& Svensson Lennart (eds.) Action and Interactive Research. Beyond Practice and Theory. Maastricht: Shaker Publishing, 63-88.

Acker, Joan (2006a) Inequality regimes, class, gender and race in organizations. Gender \& Society, 20, 4, 441-464.

Acker, Joan (2006b) Class Questions, Feminist Answers. New York: Rowman \& Littlefield Publishers, Inc.

Act on Equality between Women and Men (609/1986; amendments up to 232/2005 included). Finland. Andersson, Susanne \& Amundsdotter, Eva (2012) Developing Innovative Organisations. Using Action-Orientated Gender Research. In Andersson, Susanne \& Berglund, Karin \& Gunnarsson, Ewa \& Sundin, Elisabeth (eds.) Promoting Innovation. Policies, Practices and Procedures. VINNOVA Report VR 2012:08, 310-327. VINNOVA - Verket för Innovationssystem /Swedish Governmental Agency for Innovation System. 
Blaedel, Karen Dons (2013) Participation and Reflection in Pragmatic Action Research. Harnessing the Potential and Dealing with the Dilemmas. In Phillips, Louise \& Kristiansen, Marianne \& Vehviläinen, Marja \& Gunnarsson, Ewa (eds.) Knowledge and Power in Collaborative Research. A Reflexive Approach. London: Routledge, 64-83.

Choo, Hae Yeon \& Ferree, Myra Marx (2010) Practicing intersectionality in sociological research: A critical analysis of inclusions, interactions, and institutions in the study of inequalities. Sociological Theory, 28, 2, 129-149.

Coleman, Gill \& Rippin, Ann (2000) Putting feminist theory to work: Collaboration as a means towards organizational change. Organization, 7, 4, 573-587.

Davis, Kathy (2008) Intersectionality as buzzword: A sociology of science perspective on what makes a feminist theory successful. Feminist Theory, 9, 67, 67-85.

Drejhammar, Inga-Britt (2001) Organisations utveckling och jämställdhet. [Development of organization and equality.] Lund: Studentlitteratur.

Ely, Robin J. \& Meyerson, Debra E. (2000) Advancing gender equity in organizations: The challenge and importance of maintaining a gender narrative. Organization, 7, 4, 589-608.

The Finnish Defence Forces. (2012) Annual Report. Helsinki: The Defence Command Finland.

Frisby, Wendy \& Maguire, Patricia \& Reid, Colleen (2009) The "f" word has everything to do with it: How feminist theories inform action research. Action Research, 7, 1, 13-29.

Gatenby, Bev \& Humphries, Maria (2000) Feminist participatory action research: Methodological and ethical issues. Women's Studies International Forum, 23, 1, 89-105.

Global Gender Gap Report (2013)

http://www3.weforum.org/docs/WEF_GenderGap_Report_2013.pdf. Last accessed 1st November 2013.

Gustavsen, Bjørn (1992) Dialogue and Development. Assen: van Gorcum.

Gustavsen, Bjørn (2001) Theory and Practice: The Mediating Discourse. In Reason, Peter \& Bradbury, Hilary (eds.) Handbook of Action Research (1st edition). London: Sage, 17-26.

Heiskanen, Tuula (2006) Gender issues in action research: Implications for adult education. International Journal of Lifelong Education, 25, 5, 519-533. 
Julkunen, Raija (2010) Sukupuolen järjestykset ja tasa-arvon paradoksit. [Gender Orders and Paradoxes of Equality.] Tampere: Vastapaino.

Kautto, Mikko (2001) Nordic Welfare States in the European Context. London: Routledge.

Leinonen, Minna \& Talola, Nina \& Terävä, Sirkku \& Uosukainen, Katja (2008) Naisten ja miesten työhyvinvointi ja tasa-arvo puolustusvoimissa 2007 [Gender Equality and Well-Being at Work in the Finnish Defence Forces in 2007.] Helsinki: Maanpuolustuksen tieteellinen neuvottelukunta, sarja A $2008 / 3$.

Leinonen, Minna \& Nikkanen, Risto \& Otonkorpi-Lehtoranta, Katri (2012) Sukupuolten tasa-arvo puolustusvoimissa - Kehittämistarpeiden näkökulma asepalvelusta suorittavien ja henkilöstön kokemuksiin. [Gender Equality in the Finnish Defence Forces.] Work Research Centre, Working Papers 88/2012. Tampere: University of Tampere.

Lehtonen, Jarmo (ed.) (2004) Työkonferenssi Suomessa. [Work Conference in Finland.] Helsinki: Työturvallisuuskeskus.

Lehtonen, Jarmo \& Kalliola, Satu (eds.) Dialogue in Working Life Research and Development in Finland. Frankfurt am Main: Peter Lang.

Lehtonen, Jarmo \& Nakari, Risto (2008) From Episodes to Dialogue-Driven Change and Action. In Lehtonen, Jarmo \& Kalliola, Satu (eds.) Dialogue in Working Life Research and Development in Finland. Frankfurt am Main: Peter Lang. 231-237.

Lorbiecki, Anna \& Jack, Gavin (2000) Critical turns in the evolution of diversity management. British Journal of Management, 11, 3, 17-31.

Lundkvist, Hans \& Westberg, Hanna (2012) Doing Gender in a Local and Regional Context. An Innovative Process of Mainstreaming Gender Equality. In Andersson, Susanne \& Berglund, Karin \& Gunnarsson, Ewa \& Sundin, Elisabeth (eds.) Promoting Innovation. Policies, Practices and Procedures. VINNOVA Report VR 2012:08, 291-309. VINNOVA - Verket för Innovationssystem /Swedish Governmental Agency for Innovation System.

Lykke, Nina (2005) Nya perspektiv på intersektionalitet, [New perspectives of intersectionality.] Kvinnovetenskaplig tidskrift, 2-3, 7-17.

Madriz, Esther (2000) Focus Groups in Feminist Research. In Denzin, Norman K. \& Lincoln, Yvonna S. (eds.) Handbook of Qualitative Research (2nd edition). Thousand Oaks: Sage, 835-850. 
Maguire, Patricia (2001) Uneven Ground: Feminisms and Action Research. In Reason, Peter \& Bradbury, Hilary (eds.) Handbook of Action Research. Participative Inquiry and Practice. London: Sage, 59-69.

McCall, Leslie (2005) The complexity of intersectionality. Signs: Journal of Women in Culture and Society, 30, 3, 1771-1800.

Meriläinen, Susan (2001) Changing Gendered Practices: A PAR Project within an Academic Work Community. Helsinki: Helsinki School of Economic and Business Administration.

Meyerson, Debra E. \& Kolb, Deborah M. (2000) Moving out of the "armchair": Developing a framework to bridge the gap between feminist theory and practice. Organization, 7, 4, 553-571.

Persson, Alma (2011) Changing Boundaries, Defending Boundaries. Gender Relations in the Swedish Armed Forces. Linköping Studies in Arts and Science No. 546. Linköping: Linköping University.

Rantalaiho, Liisa \& Heiskanen, Tuula (eds.) (1997) Gendered Practices in Working Life. Houndmills, and London: Macmillan Press Ltd.

Rapoport, Rhona \& Bailyn, Lotte \& Fletcher \& Pruitt, Bettye H. (2002) Beyond Work-Family Balance. Advancing Gender Equity and Workplace Performance. San Francisco: Jossey-Bass, A Wiley Company.

Reason, Peter \& Bradbury, Hilary (2001) Introduction: Inquiry and Participation in Search of a World Worthy of Human Aspiration. In Reason, Peter \& Bradbury, Hilary (eds.) Handbook of Action Research. Participative Inquiry and Practice. London: Sage, 1-14.

Reid, Colleen (2004) Advancing women's social justice agendas: A feminist action research framework. International Journal of Qualitative Methods, 3, 3, 1-15.

Sigurðardóttir, Erla (2006) Parental leave, Care Policies and Gender Equalities in the Nordic Countries. Conference Publication. TemaNord 2010:539. Copenhagen: Nordic Council of Ministers.

Svensson, Lennart \& Aagaard Nielsen, Kurt (2006) A Framework for the Book. In Aagaard Nielsen Kurt \& Svensson Lennart (eds.) Action and Interactive Research. Beyond Practice and Theory. Maastricht: Shaker Publishing, 13-44. 
Tallberg, Teemu (2009) The Gendered Social Organisation of Defence: Two Ethnographic Case Studies in the Finnish Defence Forces. Economics and Society, 193. Helsinki: Hanken School of Economics.

Thorvaldsdottir, Thorgerdur (2007) "Equal Opportunities for All" - Intersectionality as a Theoretical Tool to Move Equality Policies Forward. http://www8.umu.se/kvf/aktuellt/ppf/tthorvaldsdottir.pdf. Last accessed 27th January 2009.

Verloo, Mieke (2006) Multiple inequalities, intersectionality and the European Union. European Journal of Women's Studies, 13,3, 211-228.

Ylöstalo, Hanna (2012) Tasa-arvotyön tasa-arvot. [Equalities in Gender Equality Development Work.] Tampere: Tampere University Press.

Yuval-Davis, Nira (2006) Intersectionality and feminist politics. European Journal of Women's Studies, $13,3,193-209$. 